\title{
SIMULATION ANALYSIS OF SUPPLY CHAIN SYSTEMS WITH REVERSE LOGISTICS
}

\author{
Shigeki Umeda \\ Management School \\ Musashi University \\ 1-26 Toyotama-kami Nerima Tokyo 176-8534 \\ JAPAN
}

\begin{abstract}
Due to environmental and ecological responsibility, enterprises are trying to reuse, remanufacture and recycle used products to reduce the negative impact on the environment. Reverse logistics is one of essential elements to implement such sustainable supply chain system. This paper proposes methodologies of simulation modeling and analysis of supply chain systems with reverse logistics flows. This paper discusses two types of reverse supply chain: PUSH-type reverse logistics and PULL-type reverse logistics. Generic models are introduced and analysis examples of individual features will be provided.
\end{abstract}

\section{INTRODUCTION}

Modern manufacturing enterprises need to collaborate with their business partners through their business process operations such as design, manufacture, distribution, and after sales service. A supply chain system is a chain of processes from the initial raw materials to the ultimate consumption of the finished product spanning across multiple supplier-customer links. It provides functions within and outside a company that enable the value chain to make products and provide services to the customers.

In the last decade, due to environmental and ecological responsibility, enterprises are trying to reuse, remanufacture and recycle the used products to reduce the negative impact on environment, especially the manufacturers of the electrical consumer products. Electrical and electronic scrap also known as e-waste or e-scrap - has increased dramatically. Requirements for corporate responsibility and sustainability are getting more urgent. The reverse logistics in supply chains is strongly related to all stages of a product development and is also a critical problem to all levels of the industry (Guide and Jayaraman 2000).

Reverse logistics systems require taking back products from customers and the repairing, remanufacturing (value-added recovery), or recycling (material recovery) the returned products. The reverse logistics makes more complicated material-flows in supply chain. There are different kinds of material-flows in a chain. One is forward flow which starts at part/material suppliers and reaches customers. The other is reverse flow which starts at customers and reaches remanufacturer or recycler. Accordingly, introduction of reverse logistics in supply chain system would have profound effects on operations such as materialhandling and procurement. This relationship is similar to arterial-flow and venous-flow in a human body.

System design and implementation of a "supply chain system with reverse-flow" would be extremely difficult in comparison with the cases without reverse-low. This is because considerations of reverse logistics would promote many issues in both configuration design phase and operations design phase. A generic method is needed to support supply chain system with reverse logistics.

System modeling technologies often provide useful operational analysis of system behaviors. The SCOR model is the most prominent process model in supply chain system (Supply Chain Council). This model provides a set of core models, which represents business processes in supply chain operations. The SCOR model includes five core models (PLAN, SOURCE, MAKE, DELIVER, and RETURN). These core models describe the detail activities of each business process. Such macro-level models are, needless to say, useful for generic system descriptions at initial stage. 
Umeda

Modeling and simulation is one of the general purpose tools to optimize designs and operations of manufacturing and logistics systems. Especially discrete event simulation provides predictions of system's behaviors potential status by "what-if scenario". Thus, simulations have been used as a powerful solution tool for various operational management problems, such as capacity planning, resource planning, lead-time planning, supplier selection, and outsourcing planning. The disadvantage of modeling and simulation is that system analysts need to implement simulation models of their own target system. This workload is very huge.

Analysts would be able to use modeling and simulation if typical generic simulation models are provided as a simulation model library in advance. In this case, the analyst chooses proper models in library, and customizes them as the need arises (Umeda and Lee 2004; Umeda and Zhang 2006; Umeda and Zhang 2010).

The objectives of this paper are (1) to propose a generic supply chain model with reverse logistics for product reuse, (2) to implement generic simulation models for the test-bed system by using generic models, and (3) to represent effectiveness of the proposed test-bed system by numerical examples. These models include component members, which enables an analyst to organize a supply chain system with reverse logistics. All models represent both material-processing logic and information-processing logic in the chain.

\section{REVERSE SUPPLY CHAIN SIMULATION}

There are not a few research works on simulation, which is more or less relevant to sustainability, ecology, and reverse logistics issues.

Adenso-Diaz et al. (2012) presented an analysis of the influence of factors affecting bullwhip in reverse supply chain by using a simulator that extends the logic of the Beer Game to reverse supply chains. Banerjee et al. (2003) examined the effects of two lateral transshipment approaches in a two-echelon supply chain network, with a single supply source at the higher echelon and multiple retail locations at the lower, through a series of simulation experiments under different operating conditions.

Chang and Zhang (2011) proposed a simulation approach to (i) evaluate the benefits of collaborative transportation management, (ii) explain the concept of carrier's flexibility, and (iii) optimize the delivery speed capability.

Chatfield et al. (2006) developed an object-oriented supply chain simulator for integrated supply chain operations. Labarthe et al. (2007) proposed an agent-based framework for the modeling and simulation of supply chains to facilitate their management.

Persson (2011) developed a SCOR model based simulation tool. Petrovic (2011) developed a simulation tool for analyzing supply chain behavior and performance in the presence of uncertainty. Holweg and Bicheno (2002) developed a participative simulation model and applied it to an automotive steel supply chain. Their scopes are especially the 'Forrester' and 'Bullwhip' effect.

Besides these discrete-event simulation approaches, there are also works using system dynamics simulations. System dynamics simulation was used to such evaluation and understanding how mitigation affect each supply chain entity performance. Besiou et al. (2012) evaluated benefits of waste recovery systems in the view points of economy, environment, and social sustainability by using a system dynamic simulation. Carvalhoa et al. (2012) represented a case study that evaluates alternative supply chain scenarios for improving supply chain resilience to a disturbance. Fiala (2005) developed a system dynamics simulation model to investigate relationships between information sharing and strategic partnerships. Vlachos et al. (2007) developed a system dynamics model for supply chain system including remanufacturing processes.

Both of approaches, more or less, argue sustainability or ecology or product life cycle. Prahinski and Kocabasoglu (2006) reviewed the literatures in reverse supply chains (RSCs) and develops 10 research propositions to be studied using empirical research methods.

Tako and Robinson (2012) surveyed 127 journal articles of both discrete-event simulation and system dynamics simulation from the view point of decision support system building for supply chain manage- 
Umeda

ment. These article are published between 1996 and 2006. Tako and Robinson (2012) also reported that five papers among them described reverse logistics issues. Reverse logistics is concerned with the recovery of products as spare parts or recycled products at the end of their lifecycle. Product recovery is driven by economical and environmental incentives, which at the same time affects companies' manufacturing and collection activities.

\section{REVERSE LOGISTICS MODELS}

\subsection{Generic model}

The aims of the proposed test-bed system is to model reverse logistics activities and to simulate them in supply chain scenarios including the used products collection, spare-parts remanufacturing, and usable materials recycling. A generic model is needed.

First, we configured models that provide regular flow in a supply chain system. This feature is composed of elements, which include a Supplier, a Manufacturer, a Retailer, a Customer, and a Chain manager. Second, we also arranged components that realize reverse flow for product reuses. These elements are "Collector", "Remanufacturer", and "Recycler". A set of these elements would be a generic supply chain model with reverse logistics (Fig.1). Data descriptions of these elements include input (information/material), output (information/material), pre-defined information, activities sequences, and performance measurement data. The summaries of activities of these elements are as follows.

Fig. 1 represents a configuration of this model. This model is based on an analogy between arterialvenous blood flows in a human body and material-flow in a supply chain. Solid lines are production generation flow (arterial-flow), meanwhile, dashed lines are reverse logistics flow (venous-flow). Arterialflows and venous-flow should be synchronized with each other. The system synchronizes venous flows with arterial flows. A set of simulation models represents the above elements was implemented as a testbed system for supply chain management incorporating reverse logistics.

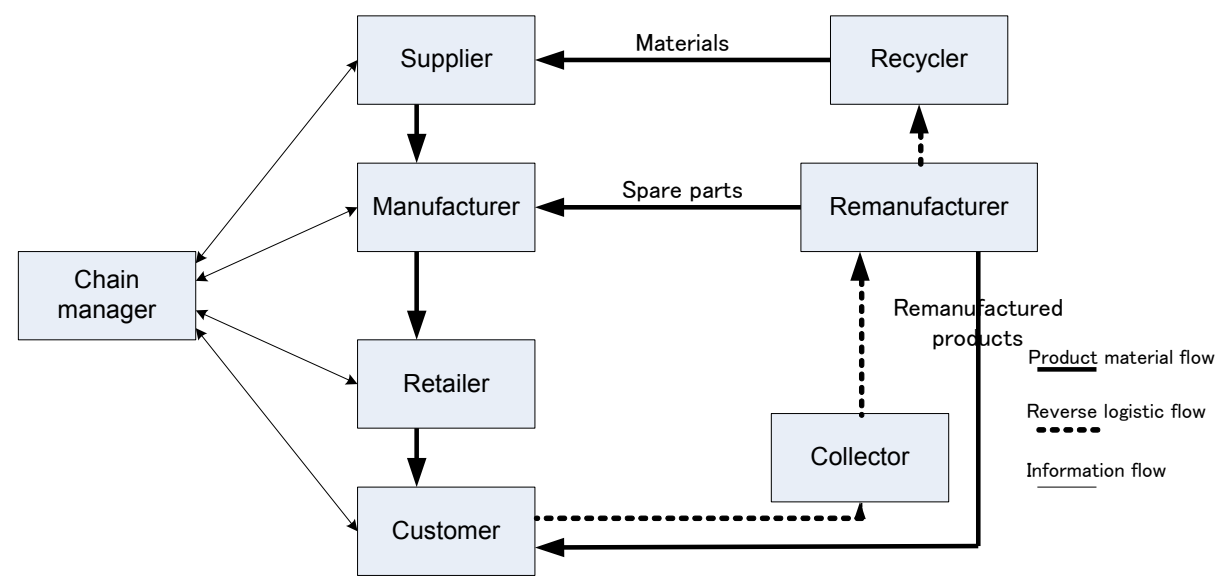

Figure 1: Generic supply chain model with reverse logistics

- Chain manager: The major task of this element is to generate orders to elements which belong to an arterial flow in a chain: these are "Supplier", "Manufacturer", and "Retailer". This is a heterogeneous element in the chain. It predicts Customers' demands, and it gives orders to other members by using the predicted data. It keeps Customers' purchase data in a particular duration, and it uses them to predict demands in next ordering cycle. We developed an IDEF0-based hierarchical function model, that represents ordering process mechanisms in a chain (Umeda 2003).

- Supplier: This element is a start point of material flows in a chain. It generates parts by a sourcing order from Chain manager. And, it sends the parts to "Manufacturer" by using a transporter. 
Umeda

- Manufacturer: It receives parts from the Supplier and keeps them. When it receives an order from the Chain manager, it starts to generate products. After predefined lead-time, it sends the products to "Retailer" by using a transporter.

- Retailer: The activities of this element are similar to Manufacturer. It receives products from Manufacturer, and it sends them to the Customer according as purchase orders.

- Collector: It reclaims used products from Customer, when he/she disposes the used product. And, it detaches reusable materials from the disposed product, and sends them to Remanufacturer.

- Remanufacturer: It produces remanufactured products by using materials from Collector. Examples of the remanufactured product are spare-parts. It provides the regenerated objects to Manufacturer.

- Recycler: It reclaims materials from wastes produced by Remanufacturer.

\subsection{PUSH-type and PULL-type reverse supply chain model}

Figure 2 represents configurations of reverse logistics models. These models are based on an analogy between arterial-venous blood flows in a human body and material-flow in a supply chain. The solid lines are production generation flows (arterial-flows), meanwhile, the dashed lines are reverse logistics flows (venous-flows). The system synchronizes venous flows with arterial flows. A set of simulation models represents above elements have been implemented as a test-bed system for supply chain management incorporating reverse logistics.

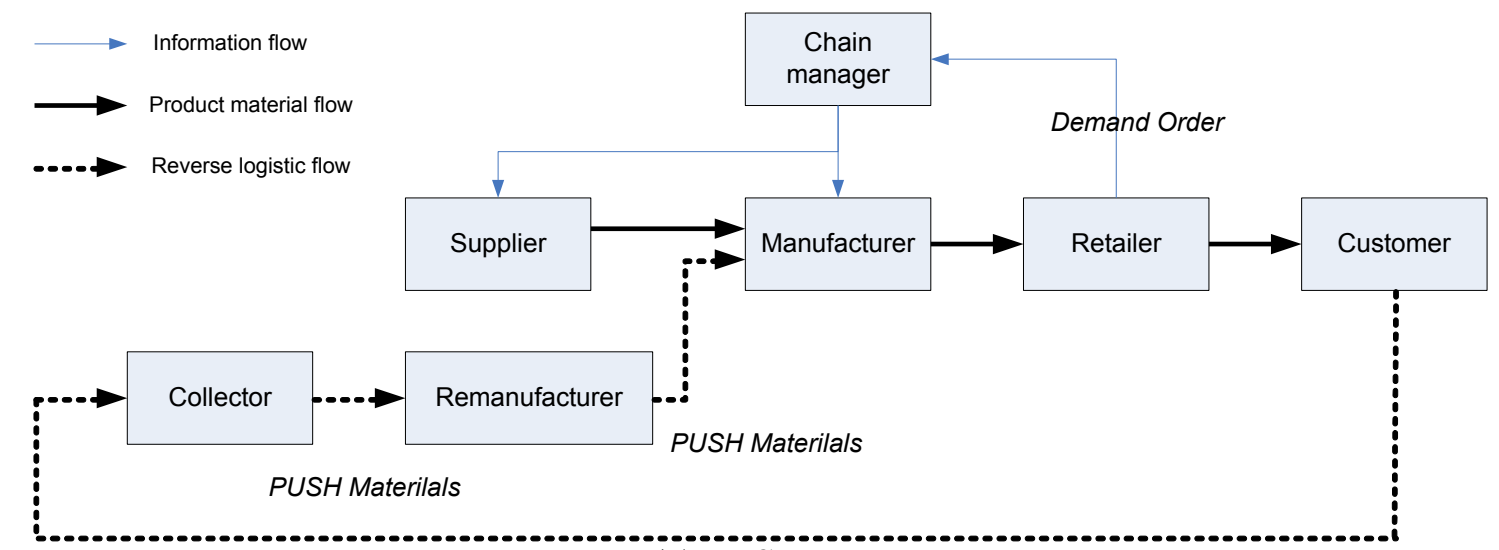

(a) PUSH-type

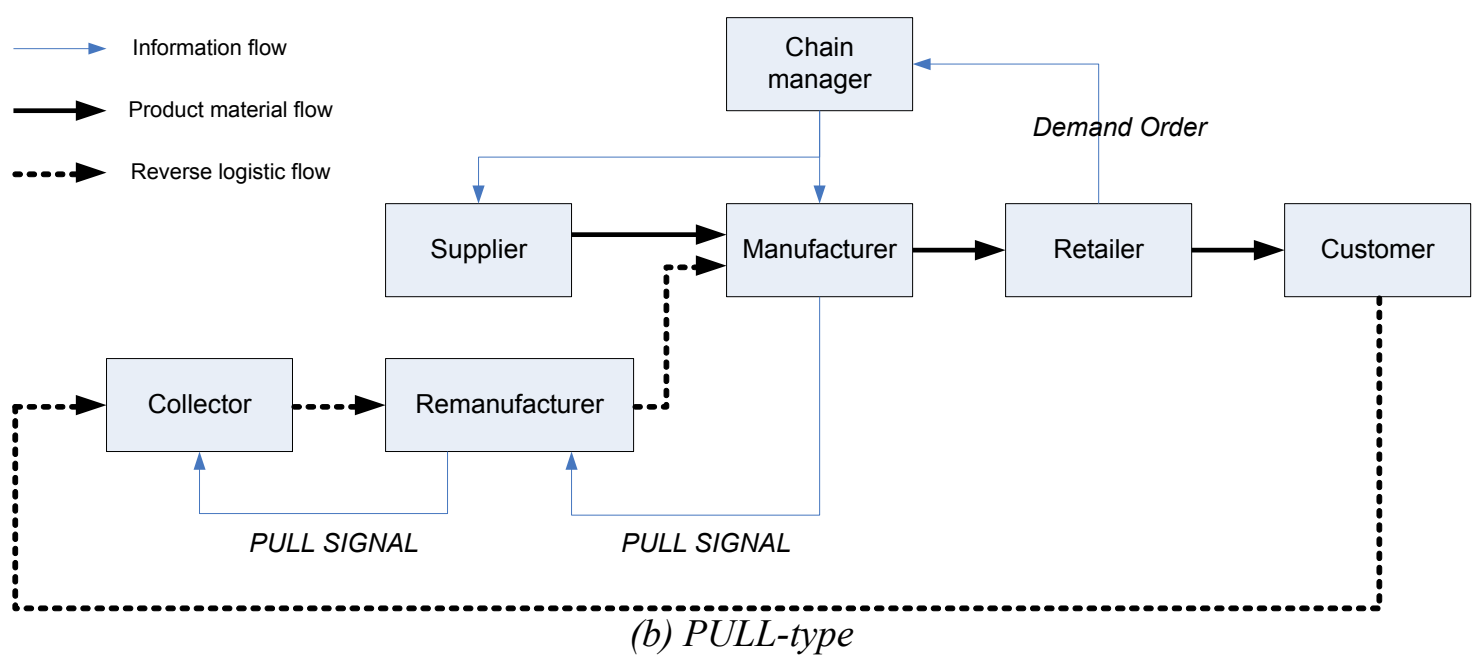

Figure 2: Push-type and Pull-type reverse supply chain model 
Umeda

The flows from Customer to Remanufacturer by way of Collector are reverse logistics flows. There are two methods to control these flows: PUSH-type and PULL-type. Customer sends "used-products" to Collector, when Customer disposes them. The role of Collector is to distinguish reusable materials from the disposed products, and stores them.

One way is that Collector and Remanufacturer sends reverse products to Manufacturer in an orderly manner. This is PUSH-type flow, which is illustrated in Fig.2 (a). Another way is that Remanufacturer regenerates reverse products as the need arises in Manufacturer. The same logic is applied in between Remanufacturer and Collector. This is PULL-type flow. The implementation of this logic needs two pull signals, which is illustrated in Fig.2 (b). The first one is from Manufacturer to Remanufacturer, and the second one is from Remanufacturer to Collector. Collector acquires reusable materials from Customer with constant collection rate. Remanufacturer pulls materials from Collector, when it requires materials. Manufacturer also pulls materials from Remanufacturer as the need arise.

In PUSH-type, remanufactured products are sequentially pushed into Manufacturer, synchronizing with occurrence of reverse. Remanufactured product would be kept as material inventory in Manufacturer. In PULL-type, reverse products are stocked at Collector. These products stay at there, during no PULL signal from Remanufacturer. And, Remanufacturer does not work until it receives PULL signal. When high volumes of reverse products are generated, they are stopped at Collector.

When demand volume by Retailer increases, volume of used product flowed to Collector would rise. These are recycled by Remanufacturer, and are stocked as refreshed parts in Manufacturer's buffer. Meanwhile, in PULL-type, even if demand volume decreases, volume of used product flowed to Collector would move down. Synchronized with the used product volume, the volume of spare parts and reuse materials would increase or decrease. When manufacturing order increases after low production continues, parts shortage is possibly occurred in Manufacturer.

\section{SIMULATION ANALYSIS}

\subsection{Experiment design}

Based on the generic supply chain model described in 3.1 and 3.2, we implemented two types of model of reverse supply chain systems. One is Push-type reverse supply chain model, and the other is Pull-type reverse supply chain model. In these models, Chain manager predicts market demands, and gives orders to both Supplier and Manufacturer in every week (5 working days).

Performance of reverse supply chain system depends on the "collection rate" of reusable materials from disposed products in market. Remanufacturer provides high performance; meanwhile Collector needs comparatively long lead-time to get reusable materials from the disposed product. Balance of these two reverse suppliers would be a key issue to determine whole of reverse supply chain system.

Other parameters of this simulation are lead-time and lot-size of chain members (Manufacturer, Retailer, Remanufacturer, Collector, and Deliverer). Chain manager generates the orders to Manufacturer and Supplier. Manufacturer and Retailer own almost same resource capacities. Meanwhile, Collector, Remanufacturer, and Retailer own almost similar resource capacities.

Operations during a hundred days are simulated, and the ordering cycle is a week (5 working days). Chain manager gives an operation order to Supplier and Manufacturer in every 5 working days. When the manager gives orders, he/she predicts demands in market by using exponential smoothing method. Each chain member gives transportation orders to Deliverer, when its operations are finished.

Parameter designs are summarized as follows:

- Simulation duration is 100 days

- The interval of Customer's orders is 5 days.

- The distribution function of Customer's order volume is a uniform distribution between 6 lots to 10 lots $(\mathrm{U}(6,10))$. 
- "Collection Rate" is a probability that the Collector gathers reusable materials from the disposed material by Customers. Two level of collection rates are provided: $60 \%$ as a high level value, and $20 \%$ as a low level value.

\subsection{Simulation results}

Table 1 represents the differences between PUSH-type reverse and PULL-type reverse. The PULL system indicates higher utilization of Collector than the PUSH system. In PUSH system, the Collector works only when the materials arrive from upstream (Customer). Meanwhile, in PULL system, Collector works to replenish inventories at the downstream (Remanufacturer). This mechanism, accordingly, makes higher resource utilization, when the Collection Rate is at low level. Figure. 3 to 6 represent material inventories transition at each supplier.

Table 1: Simulation results (Utilizations of each supply chain member)

\begin{tabular}{|c|c|c|c|c|}
\hline Model & Collection Rate & Util@Manufacturer & Util@Collector & Util@Remanufacturer \\
\hline PUSH & 0.6 & 0.92 & 0.32 & 0.30 \\
\hline PUSH & 0.2 & 0.92 & 0.12 & 0.10 \\
\hline PULL & 0.6 & 0.91 & 0.36 & 0.21 \\
\hline PULL & 0.2 & 0.90 & 0.24 & 0.16 \\
\hline
\end{tabular}

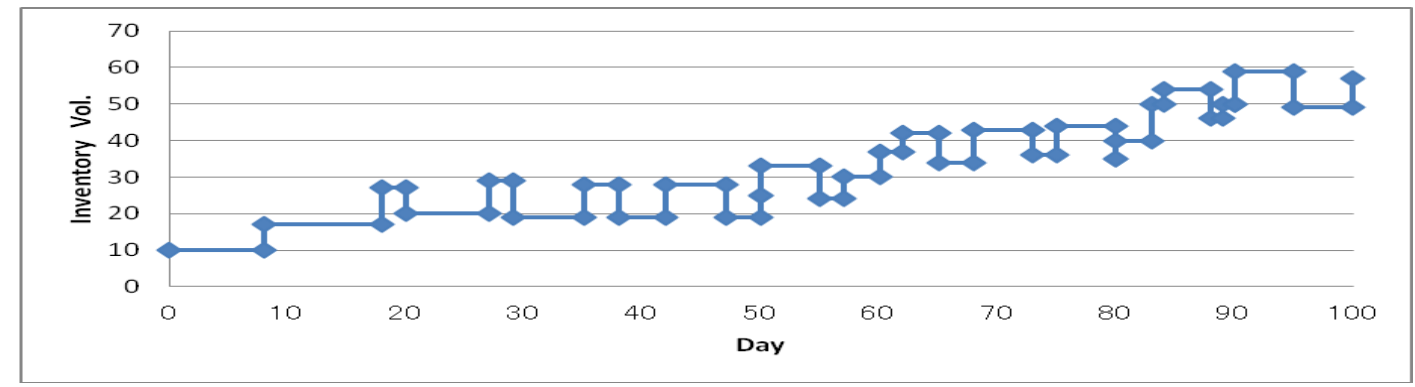

(a) Manufacturer

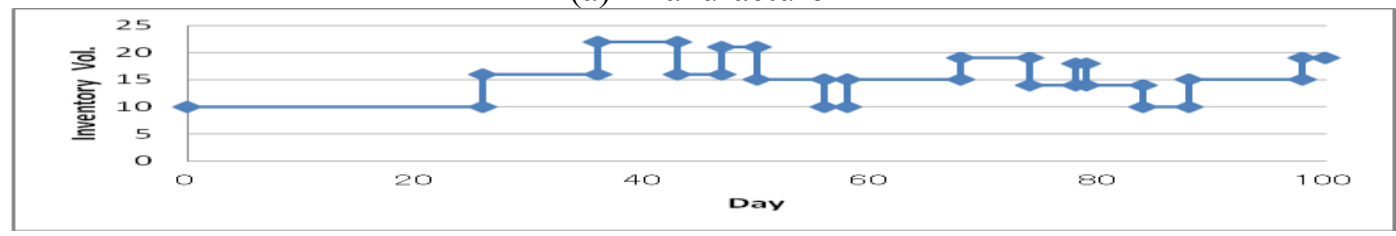

(b) Collector

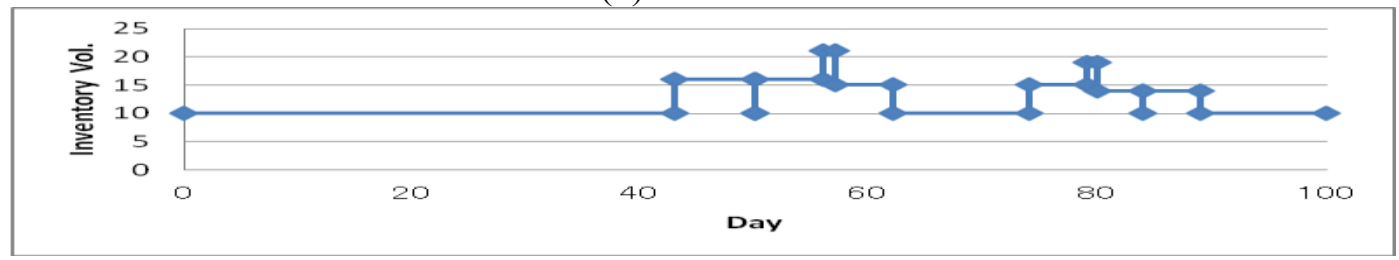

(c) Remanufacturer

Figure 3: Material inventories transition at each supplier (PUSH model, Collection Rate=0.6) 
Umeda

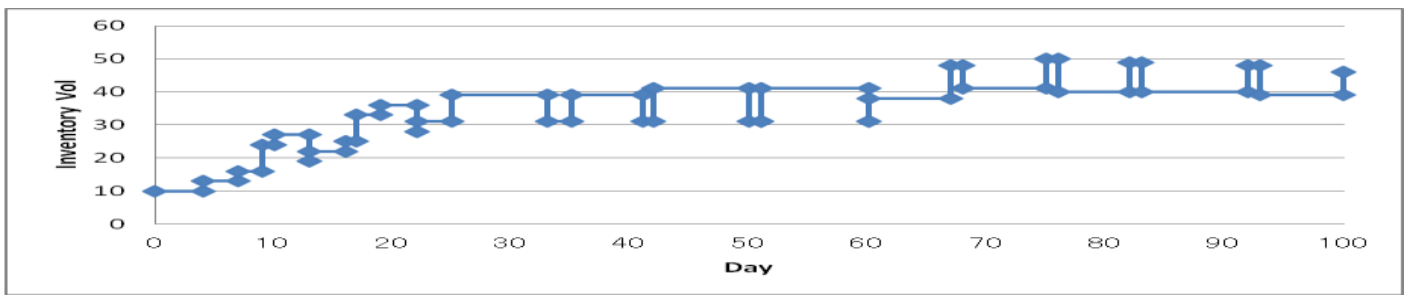

(a) Manufacturer

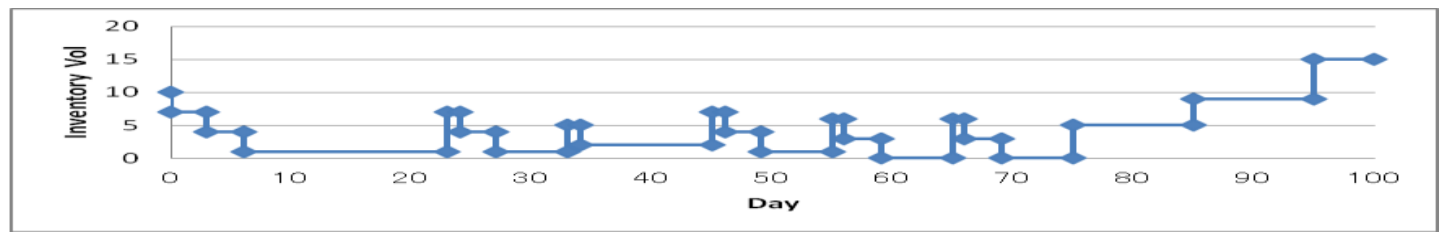

(b) Collector

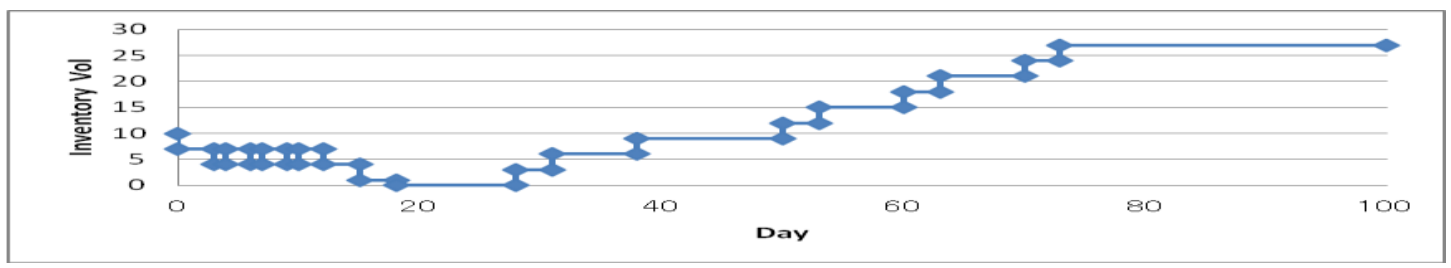

(c) Remanufacturer

Figure 4: Material inventories transition at each supplier (PULL model, Collection Rate=0.6)

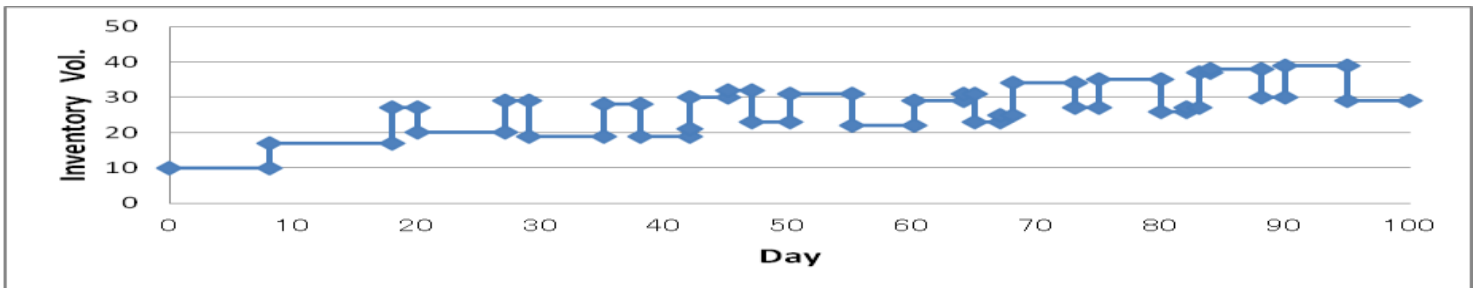

(a) Manufacturer

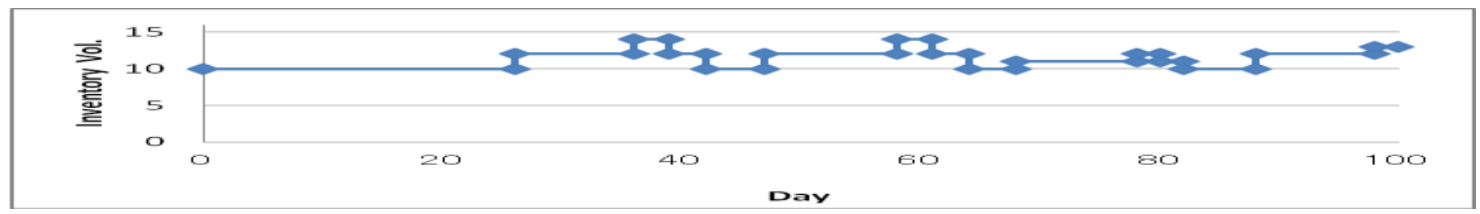

(b) Collector

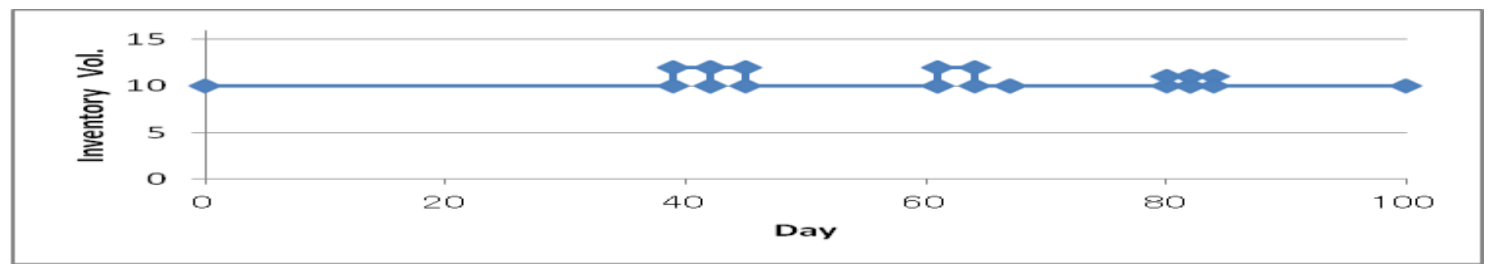

(c) Remanufacturer

Figure 5: Material inventories transition at each supplier (PUSH model, Collection Rate=0.2) 
Umeda

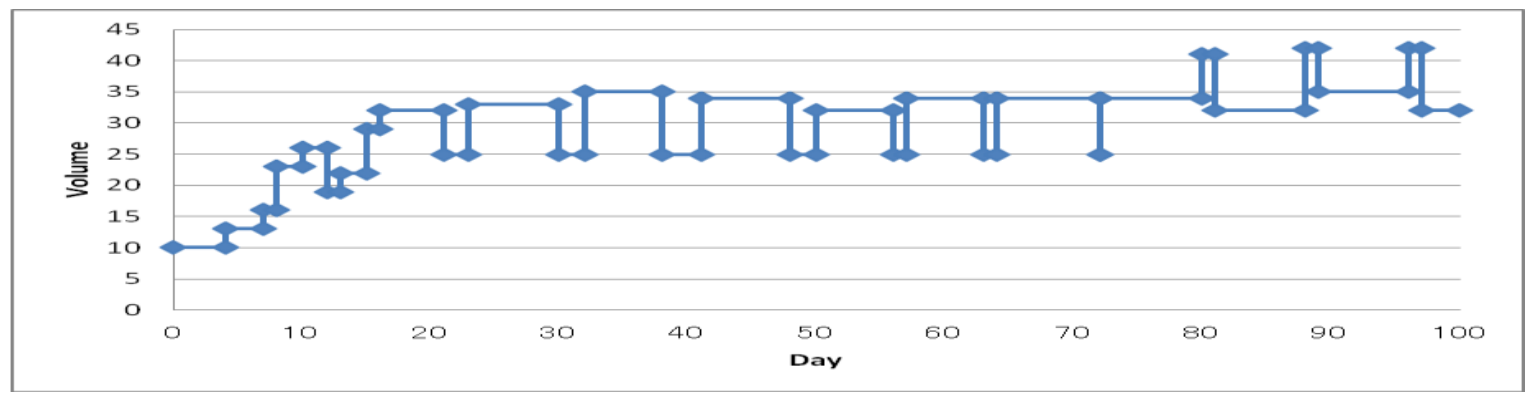

(a) Manufacturer

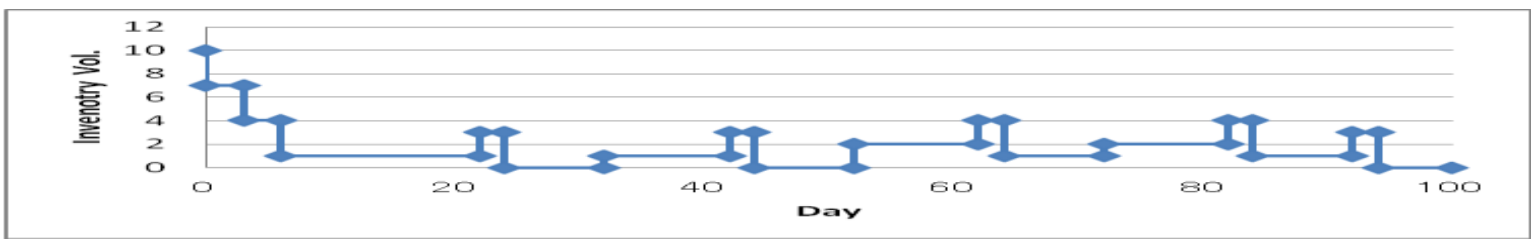

(b) Collector

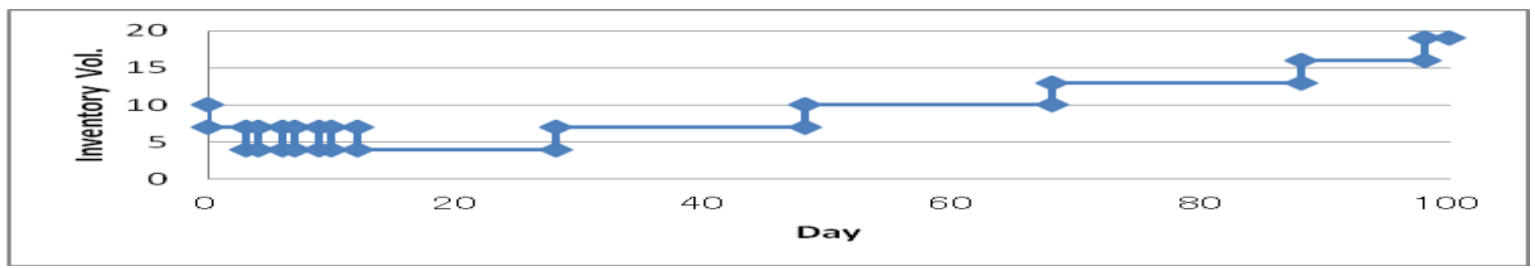

(c) Remanufacturer

Figure 6: Material inventories transition at each supplier (PULL model, Collection Rate=0.2)

\section{SIMULATION RESULTS}

In both PUSH system and PULL system, all of the reusable materials generated at Customer (market) are transferred to Collector. In PUSH system, the gathered materials in Collector are sent to Remanufacturer, which is a re-production process. After this regeneration process, materials accumulate on Manufacturer as its input materials. Meanwhile, in PULL system, the reusable materials staying at Collector would be transferred to Remanufacturer, only when the withdrawal signals from its downstream has been occurred. Therefore, reusable materials stocked in Collector demonstrates an upward trend. This reason suppresses increase of the materials in both Remanufacturer and Manufacturer.

In PUSH system, material inventory volume at Manufacturer increases according as time progress. Meanwhile, the inventories at both Collector and Remanufacturer do not fluctuate so much. PUSH system processes the collected reusable materials in sequence to produce the regenerated parts, as far as its supply continues. As a result, the input material in Manufacture keeps on increasing. (Figure 3 and Figure 5)

In PULL system, the material inventory volume at Manufacture keeps almost constant. Meanwhile, the inventories at Remanufacturer demonstrate an upward trend, and materials at Collector are consumed. In PULL system, the material consumption at Collector synchronizes with material inventory volume at Remanufacturer, and the material consumption at Remanufacturer synchronizes with material inventory volume at Manufacturer. When the Manufacturer possesses sufficient volume of input material, Remanufacturer does not need to provide Manufacturer with materials any more. (Figure 4 and Figure 6)

\section{CONCLUSION AND FUTURE RESEARCHES}

The work described in this paper is at the first stage in simulation researches for reverse supply chain management. Recovery, recycling, or reuse of products will be important issues in current supply chain 
Umeda

management. A formal study of SCM incorporating reverse logistics is critical. The proposed test-bed simulation system would be a useful tool for designing supply chain incorporating reverse logistics.

There are various types of supply and reverse chain management problems. Design and planning would be the most popular scope. When a system planner designs a supply chain or a manager reviews performance of the existing supply chain, he/she would attach importance supplier selection problem. It is a significant decision since it affects the system performance for a long time. From the supply chain performance viewpoint, it affects all the problems discussed above. Matured decisions would be needed.

We should organize problems in reverse supply chain management. Design and planning problems, suppliers/venders selection problems, and outsourcing planning problem would be discussed. These problems are interlinked. Among them, discussions of Push-type and Pull-type reverse models would be the most important.

The next stage of this simulation analysis will need to consider processes cost factors at both Collector and Remanufacturer. When the regeneration process at both Collector and Remanufacturer is expensive, the PULL system is the better choice. This is because the PULL system avoids overproductions.

\section{REFERENCES}

Adenso-Diaz, B., P. Moreno, E. Gutierrez, and S. Lozano. 2012. An analysis of the main factors affecting bullwhip in reverse supply chains, Int. J. Production Economics 135, 917-928

Banerjee, A., J. Burton, and S. Banerjee. 2003. A simulation study of lateral shipments in single supplier, multiple buyers supply chain networks, Int. J. Production Economics 81-82, 103-114

Besiou, M., P. Georgiadisb, and L. Wassenhovec. 2012. Official recycling and scavengers: Symbiotic or conflicting? Maria Besioua, European Journal of Operational Research, 218, 2, 563-576

Carvalhoa, H., A. P. Barrosoa, V. H. Machadoa, S. Azevedob. and V. Cruz-Machadoa. 2012. Supply chain redesign for resilience using simulation, Computers \& Industrial Engineering, 62, 1, 329-341

Chatfield, D. C., T.P. Harrison, and J. C. Hayya. 2006. SISCO: An object-oriented supply chain simulation system, Decision Support Systems 42, 422-434

Chang, F. T. S. and T. Zhang. 2011. The impact of Collaborative Transportation Management on supply chain performance: A simulation approach, Expert Systems with Applications 38, 2319-2329

Fiala, P. 2005. Information sharing in supply chains, Omega 33, 419-423

Guide, V. D. R. Jr, and V. Jayaraman. 2000. Supply Chain Management Incorporating Reverse Logistics, APICS Research paper Series

Holweg, M. and J. Bicheno. 2002. Supply chain simulation - a tool for education, enhancement and endeavour, Int. J. Production Economics 78 163-175

Labarthe, O., B. Espinasse, A. Ferrarini, and B. Montreuil. 2007. Toward a methodological framework for agent-based modelling and simulation of supply chains in a mass customization context, Simulation Modelling Practice and Theory 15, 2, 113-136

Persson, F. 2011. SCOR template - A simulation based dynamic supply chain analysis tool, Int. J. Production Economics 131, 288-294

Petrovic, D. 2001. Simulation of supply chain behaviour and performance in an uncertain environment, Int. J. Production Economics 71, 429-438

Prahinski, C. and C. Kocabasoglu. 2006. Empirical research opportunities in reverse supply chains, Omega 34, $519-532$

Supply Chain Council: Supply Chain Operations Reference model, http://www.supply-chain.org/

Tako, A. and S. Robinson. 2012. The application of discrete event simulation and system dynamics in the logistics and supply chain context, Decision Support Systems 52, 802-815

Umeda, S. 2003. Planning and implementation of information systems in supply chain systems, Journal of Society for Project Management, 5, 4, $42-48$

Umeda, S. and Y. T. Lee. 2004. Integrated Supply Chain Simulation - A Design Specification for a Generic Supply Chain Simulation, NISTIR 7146, National Institute of Standards and Technology, Gaithersburg, Maryland: US Dept. of Commerce. 
Umeda, S. and F. Zhang. 2006. Supply chain simulation: generic models and application examples, Production and Planning Control, 17, 2, 155-166. Taylor \& Francis

Umeda, S. and F. Zhang. 2010. "A Simulation modeling framework for supply chain analysis." In Proceedings of the 2010 Winter Simulation Conference, Edited by B. Johansson, S. Jain, J. MontoyaTorres, J. Hugan, and E. Yücesan, eds. 2011-2022. Baltimore Maryland: Institute of Electrical and Electronics Engineers, Inc.

Vlachos, D., P. Georgiadis, and E. Iakovou. 2007. A system dynamics model for dynamic capacity planning of remanufacturing in closed-loop supply chains, Computers \& Operations Research 34, 2, 367394

\section{AUTHOR BIOGRAPHIES}

SHIGEKI UMEDA is currently a professor of Management Science at Musashi University, Tokyo, Japan. Dr Umeda joined IBM after leaving school and worked at the Tokyo Research Laboratory as part of the research staff for 10 years. After leaving IBM, he worked as part of the faculty staff at the Management School, Musashi University. He also worked at the National Institute of Standards and Technology (NIST), US Dept. of Commerce, as a part of the guest research staff from 1996 to 1998 and from 2002 to 2003. His research interests include manufacturing system engineering, enterprise integration, supply chain management, business process modeling, discrete event simulation, project management, and decision science. He received his degrees from Waseda University, Tokyo, Japan. His e-mail address is $<$ shigeki@cc.musashi.ac.jp>. 